\title{
Owning Experience: Describing the experience of other persons
}

\section{Peräkylä, Anssi}

1991

Peräkylä , A \& Silverman , D 1991 , ' Owning Experience: Describing the experience of other persons ' , Text, vol. 11 , no. 3 , pp. 441-480.

http://hdl.handle.net/10138/33915

publishedVersion

Downloaded from Helda, University of Helsinki institutional repository.

This is an electronic reprint of the original article.

This reprint may differ from the original in pagination and typographic detail.

Please cite the original version. 


\title{
Owning experience: Describing the experience of other persons*
}

\author{
ANSSI PERÄKYLÄ and DAVID SILVERMAN
}

\begin{abstract}
Using conversation analytic methods on data drawn from AIDS counselling

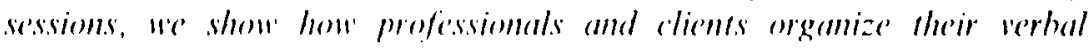
crohanges and body move'ments when talking about another's imer experiences. When the person heing discussed is present, a special problem arises. We show how this problem is constituted and resolved by all the parties collaboratively orienting to a particular organization of knowledge, where the 'owner' of the experience stands in a special relation to the descriptions. This leads to a close analysis of how the parties skilfully invoke the cxpectations of standard relational pairs (e.g. hushand wife) in accomplishing professional-client encoumters. The empirical analysis is tied to a discussion of Witgenstein's work on intentions and the prospects it holds for a 'post-Romantic' sociolog!:
\end{abstract}

Keywords: circular questioning, counselling, conversation analysis, imner experience, Willgenstein.

\section{Introduction}

Other people cannot be said to learn of my sensations only from my behaviour, for I cannot be said to learn of them. I have them.

The truth is: it makes sense to say about other people that they doubt about whether I am in pain; but not to say it about myself.

Wittgenstcin (1968, para. 246)

Wittgenstein once, while watching leaves blowing about in the wind, said about them, 'Now I'll go this way. Now I'll go that way'. That is, our evidence for intentions is before us and we need not think it is inside us. The observer has to reconstruct and guess at intentions.

Shibles (1969: 70)

$0165 \cdot 4888 / 91 / 0011 \quad 0441 \$ 2.00)$

(C) Walter de Gruyter

$7 e x 111(3)(1991), p p \cdot 441-480$ 


\section{Anssi Peräkylä and David Silverman}

In his famous observations about pain, Wittgenstein reminds us how we speak about our own experience and that of others. In normal circumstances, people are assumed to have direct access to their experiences and sensations in a way which is unavailable to others. Normally, then, we would not speak about someone 'learning' of her own experience; she would simply 'have' it. Nor would we usually expect to hear someone say that he 'doubts' his experience.

Wittgenstein is telling us that the language of cognition (and hence of doubt) is normally inappropriate when we describe our own sensations. However, such a language is appropriate when describing how someone else is feeling. Here we talk as if we have no direct access and hence present our descriptions as defeasible observations i.e. as observations which may turn out to be false. But when we describe our own experiences, it is often difficult to see how doubt would get a foothold. As Wittgenstein writes:

My 'mental state', the 'knowing', gives me no guarantee of what will happen. But it consists in this, that I should not understand where a doubt could get a foothold nor where a further test was possible.

Wittgenstein (1969, para. 356)

However, this degree of certainty about one's own mental state should not be taken to imply that understanding another person is a difficult or even mysterious process. To be a member of a culture is to be able to understand a range of contexts which provide possible readings of another's actions and words as expressions of particular motives or intentions (Hymes 1964; Frake, 1972; Coulter, 1979). So, as Wittgenstein's reported comment above on the movement of leaves suggests, when we describe another's intention, whether the other is person or object, the context suggests to us an appropriate vocabulary. Moreover, because the other can be an object, the process of understanding should not be depicted as a meeting of minds but rather as another's reconstruction of what underlies someone (something) else's behaviour. As Woolgar (1985) has implied, only essentialist assumptions about the special character of human to human communication stands in the way of a sociology of machines (concerned, of course, not with what machines think but with how, in special circumstances, thoughts or intentions may be attributed to them). ${ }^{1}$

The special task of Wittgenstein's later work was to explain how this essentialist thrust had sent philosophy down an intellectual cul-de-sac. He comments:

When philosophers use a word -- 'knowledge', 'being', 'object', ' $I$ ', 'proposition', 'name' -..- and try to grasp the essence of the thing, one must always ask oneself: 
is the word ever actually used in this way in the language-game which is its original home?

What we do is to bring words back from their metaphysical to their everyday use.

Wittgenstein (1968, para. 116)

We might reasonably suggests, however, that this argument relates to the special tasks of philosophers in elucidating the logical status of our observations. What, if at all, does it teach sociologists?

Let us suggest three contributions. First, Wittgenstein's diagnosis of philosophers' essentialism is applicable to a vast swathe of the sociological tradition. Ironically, many sociologists who are most critical of purely structural work share with the structuralists a desire to 'tell it like it is'. Their aim is to reveal the essence of people's expericnces. Their favoured method is the open-ended interview in which the subject of the enquiry is no longer passive (0)akley, 1981; 1"inch, 1984) and may even be given a position to validate the researcher's analysis (Abrams, 1984; Ball, 1984).

Silverman (1989a) has argued that such attempts to privilege "experience' are no better or worse than the attempts of popular journalism to elicit accounts (from stars, victims etc.) about 'how it feels'. Rather than try to grasp the essence of the thing, we might analyse the system of representations implicit in both the interviewer's questions and the respondent's answers. Curiously, by seeking to identify what Wittgenstein called the language game, we would be engaged in an activity of no immediate interest to the subjects concerned who routinely use the game as a resource without constituting it as a topic (Garfinkel, 1967). Consequently, attempts at members' validation may reflect a misunderstanding about the language-game of sociology (Bloor, 1983).

Essentialism always wants to look behind phenomena to discover the reality behind the appearance: the experience behind the words and gestures or, in the structural sociological tradition, the totality behind one instance (say 'family structure' or 'the organization of the scientific community'). Wittgenstein's second contribution is to remind us as sociologists that we must put on one side our everyday assumptions about the stable character of phenomena (like families, science and even experience). Instead, we are concerned with how such phenomena are constituted in a range of contexts. Thus the phenomenon (without inverted commas) always escapes (Silverman, 1989b). As Wittgenstein writes:

We feel as if we had to penetrate phenomena: our investigation, however, is directed not towards phenomena, but, as one might say, towards the 'possibilities' of phenomena. We remind ourselves, that is to say, of the kind of statement that we make about phenomena. 
Wittgenstein (1968, para. 90)

Now this activity of 'reminding ourselves' need not employ the kind of data ordinarily used by sociologists. Indeed, Wittgenstein and the later tradition of ordinary-language philosophers are usually quite happy to work with invented examples which rely for their force upon their inventor's and reader's common culture. Therefore, Wittgenstein's work is not empirical in the way which most sociologists use that term.

However, in following Wittgenstein's injunction 'to bring words back from their metaphysical to their everyday use', we are forced to put on one side our unthought assumptions in order to investigate an unexplored territory. This is Wittgenstein's third contribution: the encouragement to drop our essentialist or romantic blinkers and to investigate everyday practices.

We pursue this task here by examining a topic close to Wittgenstcin's interests but using a form of data that he never discusses. Based on transcriptions of audio or videotapes of episodes of AIDS counselling, our analysis focusses on how professionals and clients talk about someone else's experiences.

Unlike romantic sociologists, we do not claim to describe the experience of someone else, for, as with other phenomena, we wish to approach 'experience' like this (i.e. within inverted commas). In so doing, we tread a path foreshadowed in schematic work on 'vocabularies of motive' half a century ago (Mills, 1940) and more recently developed in conversation analytic work including Sacks (1974), Sacks et al (1974) and Levinson (1988)

This path does not lead to the heart-warming tales and shock revelations of tabloid journalism or romantic sociology. Instead its focus on the mechanics of describing experience seeks to explicate the apparatus which we are already adept at using. This means that we are more concerned with routines than with what Wittgenstein calls 'curiosities'. As he puts it:

What we are supplying are really remarks on the natural history of human beings; we are not contributing curiosities however but observations which no one has doubted, but which have escaped remark only because they are always before our cyes.

Wittgenstein (1968: para. 415)

\section{'Circular questioning': talking about others}

In the following, we examine some aspects of a particular practice found in HIV/AIDS counselling sessions applying the Family-Systems 
approach. The data are from a clinic in the UK, specialized in the treatment of HIV-positive patients. Apart from the patient, in such counselling sessions his or her close relations are often present: lovers, family-members, or the like. Following a practice called 'circular questioning' in family therapy theory (see Selvini et al., 1980; Penn, 1982; Mauksch and Roesler, 1990), the patient or his/her relation is regularly asked by the counsellor to describe something related to the experience of the other client. These descriptions may concern external states of affairs related to the other party (i.e. the $\mathrm{C}$ can ask a mother to describe her ideas of the side-effects of a medication offered to her son), or his or her mental states.

We will concentrate here on the descriptions of mental states. A patient may be asked to describe what his wife is worried about, or a mother may be asked to describe how the patient sees his chances of developing AIDS, and so on. These descriptions of the inner experience of other people take the participants and the analyst into Wittgenstein's problematic. Namely, the person producing a description of another's inner experience is asked to talk about something she has a limited access to; while the one with the direct access is one of the hearers.

Let us begin with an example (see the Appendix for transcription conventions). This is taken from a consultation with a patient (a gay man) and his boyfriend; the patient has recently been diagnosed as HIV positive. The production of this lengthy example is perhaps justified, because it sets the scene for all the forthcoming analyses.

(1) (E3.29)

$$
\begin{aligned}
& \mathrm{C}=\text { Counsellor; } \mathrm{P}=\text { Patient; } \mathrm{BF}=\text { Patient's boyfriend } \\
& 1 \text { C: What are some of things that you } \\
& 2 \text { think E:dward might have to do. }=\mathrm{He} \\
& 3 \text { says he doesn't know where to go from } \\
& 4 \text { here maybe: and awaiting results and } \\
& 5 \text { things. } \\
& 6 \quad(0.6) \\
& 7 \text { C: What d'you think's worrying him. } \\
& 8 \quad(0.4) \\
& 9 \text { BF: Uh::m hhhhhh I think it's just fear } \\
& 10 \text { of the unknow:n. } \\
& 11 \text { P: Mm[: } \\
& 12 \text { C: [Oka:y. } \\
& \text { 13 BF: [At-at the present ti:me. (0.2) } \\
& 14 \text { Uh:m (.) once: he's (0.5) got a } \\
& 15 \text { better understanding of }(0.2) \text { what }
\end{aligned}
$$




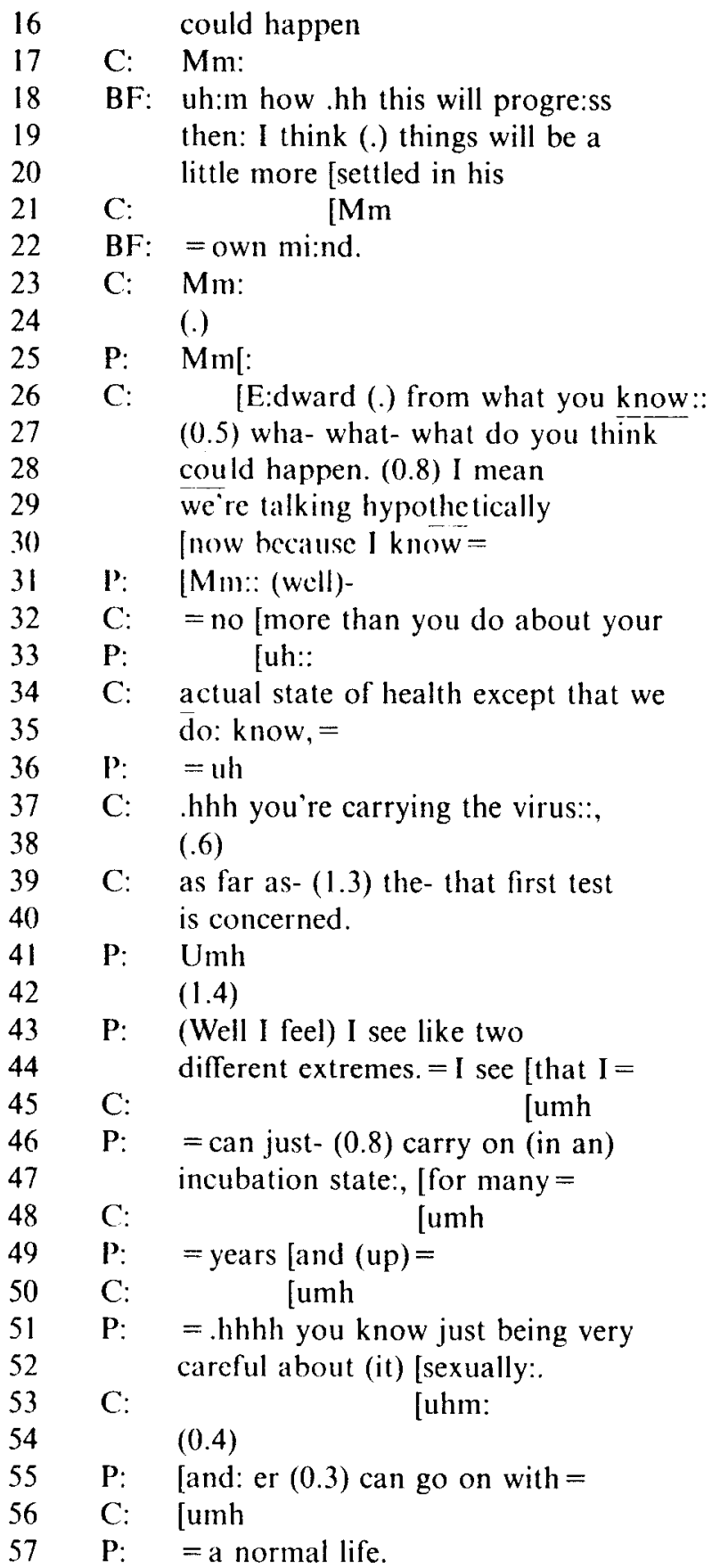




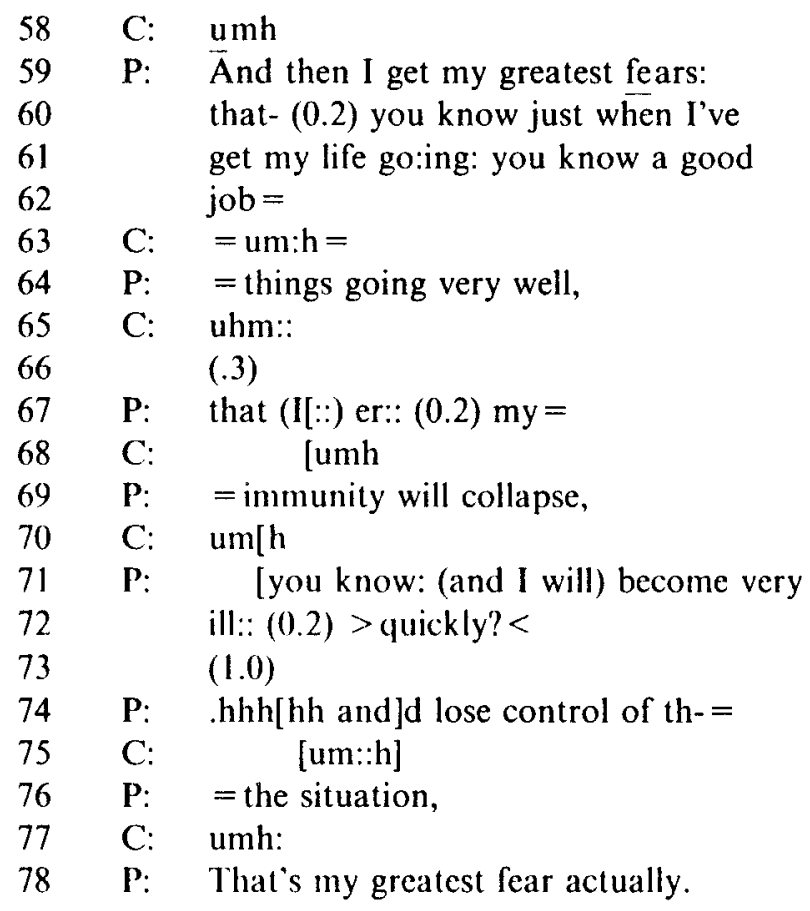

In (1), the $\mathrm{C}$ makes an enquiry directed to $\mathrm{BF}$, concerning the worries of the patient. After some preparations in the beginning of the turn, ${ }^{2} \mathrm{C}$ ends up asking $\mathrm{BF}$ simply what he thinks is worrying $\mathrm{P}$. Whereas the first part of C's turn (lines 1-5) could be heard as a part of an invitation to produce a description of external states of affairs related to Edward's life, the concluding line 7 unequivocally elicits a description of his mental state. BF then produces his version of P's worries. The C thereafter directs her enquiry to the $P$ himself asking what are his views about the future risks. The enquiry leads $P$ to produce a long and detailed narrative about his fears.

\section{Owner's privileged right to the next turn}

In an ordinary conversation, if $\mathrm{A}$ produces an utterance which is addressed to $\mathrm{B}$, but the informational or attitudal content concerns primarily C, C is usually expected to respond. That is the case in (2), which is an excerpt used originally by Sacks et al (1974), and analyzed further by Levinson (1988: 166-167): 
(2) (Levinson, 1988)

1 Sharon: You didn't come tuh talk tuh Karen?

2 Mark: No, Karen - Karen' I're having a

3 fight,

$4 \quad(0.4)$

5 Mark: After she went out with Keith an not

6 with (me)

7 Ruthie: Hah hah hah hah

8 Karen: Wul, Mark, you never asked me out

According to Levinson, although Karen obviously is not the addressee of Mark's turn above, the fact that the remark is delivered in Karen's presence, and that it is a report of a 'fight' and an imputation of blame, picks out her as a recipient who may be expected to respond to the complaint. In relation to Mark's utterance, Karen has a particular participation status; this is incorporated in the expectation that she will respond.

In counselling sessions, immediate responses like the one above are not regularly seen. Given that the counsellor and the client regularly are aligned as a questioner and an answerer, the counsellor usually takes (and is given) the next turn after any client turn (cf. Peräkylä and Silverman, in press). But after having elicited a description of a client's inner experience from another client, counsellors regularly allocate the next turn to the client concerned. In other words, the standard structure of the sequence when such descriptions are made is the following:

(1) C: Invites P1 to produce a description of something related to P2's inner experience

(2) P1: Produces the requested description

(3) $\mathrm{C}$ : Invites $\mathbf{P} 2$ to respond to the description given by $\mathbf{P 1}$

(4) P2: Produces the response

There are two noteworthy issues in the structure of this standard sequence. Firstly, stages (1) and (2) regularly lead to stage (4). Indeed, thus far we haven't come across any exceptions to this. In most cases, (4) is preceded by the counsellor's invitation (stage 3); but it also can be volunteered so that stage (3) is omitted. In other words, as soon as another person's version of someone's experience is given, the person in question is due to respond.

Secondly, the other client's description of someone's inner experience never comes after the description that the person him/herself has given about his or her inner experience. In our corpus, there is only one exception to this, and we will analyse it in detail later.

The fact that the sequence in describing other's experience regularly 
appears in this particular format, indicates that the participants orient to a specific organization of knowledge in shaping their interaction. The inner experience of somebody appears as a very special kind of object: as something about which the person in question regularly is given the opportunity to produce the final, authoritative description. In this way, the person in question is systematically treated as having a qualitatively different relation to the object in question. He or she is treated as the owner of the experience (cf. Sharrock, 1974).

The knowledge that the owner of the experience has about his or her mind is systematically treated as belonging to a different kind of category than the knowledge that others may have about it. The difference between the owner's direct access to his mind, and the limited access that anybody else has to it (Pomerantz, 1980), is embodied in the recurrent and public sequential pattern of conversation in counselling sessions. ${ }^{3}$

The analysis that follows secks to show how the actors collaboratively, step by step, orient to this particular organization of knowledge also in the details of their interaction. During the course of the invitation and production of the description of somebody's inner experience, the participants build up the relevancy of the owner's forthcoming response. After having showed this, we will shortly evaluate the significance of these findings regarding the analysis of counselling as an institutional form of talk.

\section{Use of agenda statements}

The most obvious, and perhaps most simple, practice of displaying the particular organization of knowledge and creating the relevancy of the P2's response about the P1's version of his experience is an agenda statement. Here the counsellor formulates a scheme for the forthcoming interaction in relation to the initial invitation to produce a version. Such a formulation is used in (3).

(3) (E3.007: 2-7)

$\mathrm{W}=$ Patient's wife

1 C: And how [would you see $=$

2 P: [heh heh heh

3 C: = things going at work

4 C: $\rightarrow$ Mary. = D'you think- I mean just let's

5 hear your view of it before we check

6 [with

7 W: [What for him?

8 C: Ye:s. 
Here the counsellor produces an agenda statement in connection with the initial invitation for $W$ to produce a description related to P's experience. ${ }^{4}$ P's authority is recognized, and his opportunity to respond later is projected, when C says 'before we check with', which refers obviously to the $P$.

The agenda statement is here located as a self repair. The $\mathrm{C}$ cuts off a sentence which she has begun ('D'you think-'). Producing the agenda statement may thus be related to C's perception of some troubles in the reception of the invitation. W's repair initiator in line 7 equally hints at the existence of some troubles. For example, it may be unclear to $\mathrm{W}$ whose work (her or P's) $\mathrm{C}$ is referring to.

While projecting a space for P's response later, the agenda statement seems to have a double function. First, it picks up the invited description as something that the patient is asked to monitor in a special way, in order to be able to conlirm or rebut it later. This also emphasizes his special recipient status regarding the forthcoming talk. Second, while locating P's response 'later', it works as a device to delay the production of this. By securing the delay, the agenda statement also works towards maintaining the mediated character of the production of description of another's experience. The patient whom the version is about is not expected to respond spontaneously, but rather after an invitation by the counsellor ('before we check with').

As said above, an agenda statement is the most obvious practice projecting the other patient's response to the descriptions related to their experience. It is not, however, used in most cases; its use may indeed be related to a perception of troubles in the invitation of the version.

In the following sections we will see that all the participants are collaboratively occupied with displays of the relevance of the other patient's response even where no agenda statements are used.

\section{Qualifying the descriptions}

One practice creating the relevancy of the owner's forthcoming turn of talk is related to the design of the utterances in which descriptions of other's experience are invited or produced.

Regularly, when Cs are requesting Ps to produce descriptions of other's experience, and equally when Ps are actually producing those descriptions, the references to other person's experience are not made in a straightforward manner. Recurrently, they are qualified in one of three alternative ways.

The first type of qualification is embedding the descriptions (or invit- 
ations to produce them) in references to the producer's own experience. That is the case in (4), excerpted from (1) above.

(4) (E3-29: 27-31)

7 C: What d'you think's worrying him.

$8 \quad(0.4)$

9 BF: Uh::m hhhhhh I think it's just fear

10 of the unknow:n.

Here the counsellor does not ask BF 'what is worrying him?', but rather 'what d'you think's worrying him'. Consequently, BF prefaces his response with 'I think' rather than describing directly his partner's experience. In the first place, 'what d'you think' and 'I think' downgrade the knowledge claim involved in the question and the answer. This displays an orientation to BF's limited access to P's mind. On the other hand, the use of these phrases may also betray an orientation to BF"s direct access to his own mind: he is requested to report, and reports, his own thoughts - and as a report of BF's thoughts, these descriptions are straightforward and not qualified.

When the counsellors invite patients to describe their own current experiences, the questions and answers regularly do not show this embedded structure. That is the case in (5) and (6):

(5) (E4: 16)

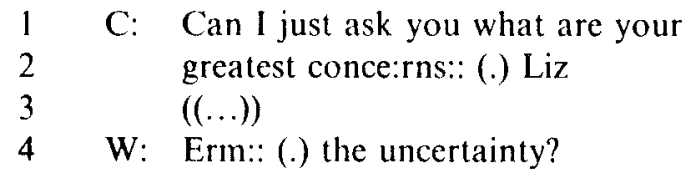

(6) (E4: 46)

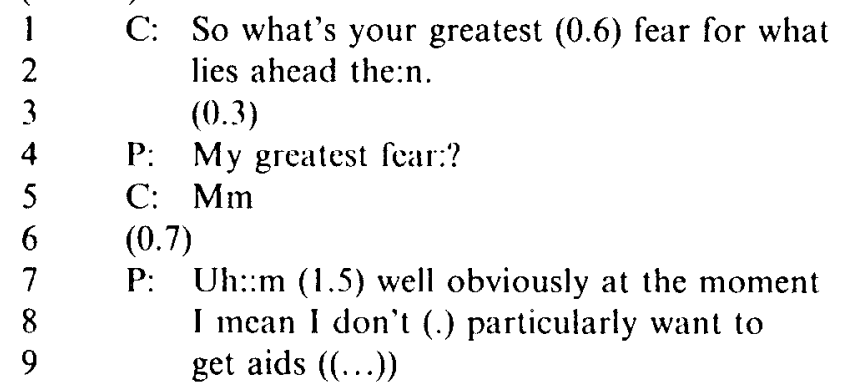

In (5) and (6) above, both counsellor and the clients produced the descriptions of experience in a straightforward manner. ${ }^{5}$

'I think' seems indeed to be the most common way to embed the descriptions of other's experience. It is very often used by the patients, 
and almost always it appears in counsellors' invitations (as the formula 'what do you think ...'). It seems to have a double function: apart from embedding the description in the describer's experience, it also downgrades the knowledge claims involved. There are, however, other ways of embedding which, on the contrary, upgrade the knowledge claim. Consider the following:

(7) (E3-29)

$$
\begin{array}{lll}
1 & \text { C: } & \text { Carl do you th- what do you think } \\
2 & & \text { might be Edward's main concerns } \\
3 & & \text { today. (.) I mealn you said your }= \\
4 & \text { P2: } & \text { [Mm } \\
5 & \text { C: } & =\text { health but is there anything else. } \\
6 & & (0 . \overline{8}) \\
7 & \text { P2: } & \text { Well of course I'm sure he's worried } \\
8 & & \text { about his resu:Its, }
\end{array}
$$

C above uses the standard 'what do you think' formula; and in addition to that, she produces another qualifier 'might'. P2, however, claims to be sure about what he is saying. But nevertheless, the description is embedded. He does not report in the first place that his partner is worried about his results, but rather that he is sure that his partner is worried about his results. 'Being sure' is a description of the speaker's experience. While upgrading the knowledge claim, it, too, attends to the limited access that P2 has to the issucs described. By claiming certainty, P2 implies that this is something he can be sure or unsure about. For P1 (the owner of the experience) such a question would not normally arise.

But, in some cases, the speakers seem to be satisfied with a mere expression of uncertainty when describing another's mind. This is the second type of qualification. It is used in (8).

(8) (E3-45: 4-10)
1 C: D'you think mum's got any concerns at
3 talk about.
2 the moment that she would want to
$4 \quad(0.2)$
$5 \quad$ P; Oh she mi- she might be worried about
6 the side-effects.

The display of uncertainty seems to be attending here to the problems of inaccessibility of other persons' experience. Again, it would not usually make sense for P to say about himself that 'I might be worried about the side-effects', because he is expected to know what he is worried about. But concerning his mother's worries, this is a valid description. 
The third type of qualification is used by the clients more than the counsellors. After having been invited to produce a version of the coclient, the clients can transpose the focus of the discourse. Rather than describing the other's experience directly, they can describe the publicly available facts indicating the co-client's experience. Typically, this can be done by referring to the owner's earlier reports of his experience. This is the case in (9) below.

(9) (E3.5)

1 C: And how do you find (.) Tom coping

2 o:n (.) the AZT?

3 W: He seems to be all right.

$4 \quad \mathrm{C}: \mathrm{Mm}[?$

5 W: - [He says he doesn't feel any worse

6 than he did before

In (9), W first produces a short account of Tom's experience, 'He seems to be all right.' This is marked as uncertain by prefacing it with 'seems'. After W's account, C produces a continuer (line 4), which prompts an elaboration of the initial response. Now $\mathrm{W}$ transposes the focus of discourse by reporting Tom's own descriptions of his 'coping'. By referring to Tom's own words, W gives evidence to support her initial account. By doing this, she also displays an orientation to Tom's (the owner's) account as being more authoritative than the one she has produced.

In sum, all three types of qualifications that the speakers use display their descriptions as tentative in comparison to the descriptions that the person in question - the owner of the experience - would be able to produce. Given that the owner is co-present when the descriptions are elicited and produced, this design of turns creates the relevancy of the owner later producing a more valid description. In other words, as soon as $C$ has asked a question, the answer of which is based on limited access to the relevant knowledge, the expectation of a turn later by the 'owner of the experience seems to be there, publicly displayed in the details of the design of the questions and the answers.

\section{Speakers recognize the ownership of experience through body-movement}

As a general rule, speakers in a conversation usually orient posturally to their addressees during the course of their turns. Typically, they gaze at the addressee at the beginning and/or end of the turn (see Goodwin, 1981; Heath, 1986). Gaze can also be used as a means of selecting the 
addressee if there are several people participating the conversation (Goodwin, 1979: Levinson, 1988).

Apart from address, the speakers' postural orientation and gaze may be related to the content of their utterances. Goodwin (1984) provided a detailed single case analysis linking participants' postural orientation with the content of a story that was being told to them. In Goodwin's case, everybody in this party who was gazing at somebody, gazed at the 'principal character' of the story when its punchline reached its conclusion.

Our analysis follows the path opened by Goodwin. The speakers describing other persons' inner experience display posturally their recognition of the owner's presence. The speakers regularly divide their orientation between the person they are describing and the counsellor who asked the questions.

Most often it seems to be the case that the patient describing his relation's experience orients to this at the beginning of the turn. There are also cases where the speaker's orientation alternates between $\mathrm{C}$ and the relation during the course of the turn. An example of orienting to the relation at the beginning of the turn is the excerpt that we examined in the previous section ( 8 , repeated here as 10$)$.

(10) (E3.45: 4-10)
1 C: D'you think mum's got any concerns at
2 the moment that she would want to
3 talk about.
$4 \quad(0.6)$
5 P: Oh she mi- she might be worried about
6 the side-effects.

On the verbal level, P's turn is obviously addressed to $C$ who asked the question. Mum is referred to in third person, which rules out the possibility of her being the addressee. However, the postural orientation of the participants does not fully coincide with this. ${ }^{6}$

(p)

C: D'you think mum's got any concerns at the moment

P: (c)

$\mathrm{M}$ : (md)

\section{(p)}

C: that she would want to talk about. (------)

P: (c) -

M: (md) 
(m) $\ldots \ldots \ldots(\mathrm{c})$

P: Oh she mi- she might be worried about the side-

C: (p)

$\mathrm{M}:$ (md)

(c) -

P: effects.

C: $\quad(p)-$

M: (md)

In (10), $\mathrm{P}$ turns towards his mother when $\mathrm{C}$ has completed her invitation for him to describe mother's concerns. He then begins his answer to C's question in an orientation to mother rather than to the questioner. The mother, however, does not symmetrically orient to the speaker. She thus declines being the recipient of P's turn. P makes a renewed turn beginning (this being a standard measure in the cases when a recipientship has not been achieved: see Goodwin, 1984: 230), re-orients to the C, and produces the full turn in an orientation to her.

What is of a particular interest in the excerpt above, is the collaborative way that the division of P's orientation between $\mathrm{C}$ (the addressee) and mother (the party whose experience is described) is achieved. $\mathrm{C}$ is constantly orienting to $\mathrm{P}$, thus displaying a potential recipientship throughout the excerpt. Mother, for her part, is displaying noncommitment all the time. P chooses to turn towards mother in the beginning of his turn, thus in body movement treating her as an addressee. P's body movement and the words he uses then contrast with each other in terms of the commonsensical rule that speakers gaze at their addressees. P's orientation to mum is not, however, encouraged by the other participants. Concurrently, he realigns himself towards $\mathrm{C}$.

It is, however, by no means a rule that the persons described withhold their orientation from the speaker. In (11) below, the person described orients first to the (projected) speaker, and maintains this orientation longer than the speaker orients to him.

(11) (E3.5)

C: And how do you find (.) Tom coping o:n (.) the AZT?

W: He seems to be all right.

C: $\mathrm{Mm}[: ?$

W: $\quad$ He says he doesn't feel any worse than he did before

The transcription of the body movement is as follows. 
(w)

C: And how do you find (.) Tom coping o:n (.) the AZT?

W: (c)

P: (c)

(w)

$(w)$

(p)

C:

$\mathrm{Mm}[?$

W: $\bar{H}$, seems to be all right. [He says he doesn't

P: $\quad(w)$

C: $\quad(p)$

..... (c)

W: feel any worse than he did before

P: (w) (w.

As with (10), in (11) above we have collaborative production of the division of speaker's orientation between $\mathrm{C}$ (the primary addressee of the answer) and the person the description is about. But now the collaborative component seems instead to enhance the speaker's orientation to the owner of the experience rather than to the addressee. $\mathrm{P}$ is the first one to reorient: he shifts his gaze to $\mathrm{W}$ as soon as $\mathrm{C}$ has made it clear that the question will be about his coping. $\mathrm{W}$ then orients towards $\mathrm{P}$ at the outset of her answering turn. After the initial gloss ('He seems to be all right') and C's continuer, W continues her turn with an unpacking component ('He says he doesn't feel ...). During this component, she realigns towards the questioner $(\mathrm{C})$. The questioner, however, has in the meantime aligned towards the owner.

The general pattern of the speakers' orientation in (10) and (11) is then the same: the speakers oriented at the beginning of the turn to the person whose experience they were describing, and only thereafter did they align towards the questioners. Through this practice, the speakers recognized the special participation status of the person to whom they first turned (Goffman, 1981). By allocating the owners a special participation status, the speakers display an orientation to the organization of knowledge where the owner stands in a special relation to the objects talked about.

The owner of the experience recognizes the ownership during the course of the turn

The special relation between the person described and the description is not only established by the speaker and the questioner, but also by the 
'owner' of the experience himself. In many cases, namely, the owner produces acknowledgement tokens or other response items during the course of the delivery of the description of his/her experience. Let us return to (1), an excerpt from which is repeated here as (12):

(12) (E3.29)

$\begin{array}{rll}7 & \text { C: } & \text { What d'you think's worrying him. } \\ 8 & & (0.4) \\ 9 & \text { BF: } & \text { Uh::m hhhhhh I think it's just fear } \\ 10 & & \text { of the unknow:n. } \\ 11 & \text { P: } & \text { Mm[: } \\ 12 & \text { C: } & \text { [Oka:y. } \\ 13 & \text { BF: } & \text { [At- at the present ti:me. (0.2) } \\ 14 & & \text { Uh:m (.) once: he's (0.5) got a } \\ 15 & & \text { better understanding of }(0.2) \text { what } \\ 16 & & \text { could happen } \\ 17 & \text { C: } & \text { Mm: } \\ 18 & \text { BF: } & \text { uh:m how hh this will progre:ss } \\ 19 & & \text { then: I hink (.) things will be at } \\ 20 & & \text { little more [settled in his = } \\ 21 & \text { C: } & \text { [Mm } \\ 22 & \text { BF: } & =\text { own mi:nd. } \\ 23 & \text { C: } & \text { Mm: }\end{array}$

Here in line 11, P produces a token 'Mm:' as a response to BF's turn that is describing his worries. In counsellor's query that was preceding $\mathrm{BF}$ 's turn, $\mathrm{P}$ was not projected as the primary address of BF's turn (that role was allocated to the $\mathrm{C}$ as the asker of the question). Usually the response items are produced by the addressees; but now $\mathrm{P}$ chooses to produce one as well.

The transcription of the body movement reveals how P's acknowledgement token is coordinated with the body movement of the speaker and himself. ${ }^{7}$

(p)

BF: Uh::m hhhhhh I think it's just fear of the unknown:n.

C:

P: $\quad$...(bf)

$\ldots(\mathrm{c})$

P: $\quad \mathrm{Mm}[:$

C: $\quad$ [Oka:y.

(c) -

BF: [At-at the present 
In the beginning of BF's turn, we have the typical pattern in which the speaker (BF) divides his orientation between the primary addressee (C) and the person whose experience he is describing (P). BF begins his turn in an orientation towards $\mathbf{P}$, whose experience he is describing. $\mathbf{P}$, too shifts his orientation towards him during the beginning of the turn. Much of the initial gloss, then, is produced when the speaker and the person whose experience is described are mutually oriented. This is dissolved at the end of the gloss. The speaker shifts from an orientation to $\mathrm{P}$ to an orientation to $\mathrm{C}$ simultaneously with the production of the last word of this initial gloss. At the completion of the last word, the $\mathbf{P}$ concurrently starts to withdraw from the orientation to BF, in order to adopt a position where he gazes down.

The acknowledgement token of $P$ (owner) is uttered in this slot: BF (speaker) has just shifted his orientation away from $P$, and $P$ himself, as a response, has withdrawn from active gestural participation. At this stage it suffices to say that the acknowledgement token of $P$ is anticipated by the speaker's orientation to him. By producing the acknowledgement token after having been gazed at by the speaker, he seems to confirm his special involvement in the issues addressed.

Another kind of acknowledgement of the ownership is done by $P$ in (13). In this case, we don't examine the owner's response to a description of his mind, but something happening prior to it, namely an owner's response to a request directed to a co-client to produce such description.

(13) (E3.49)

$\begin{array}{lll}1 & \text { C2: } & \text {.hh Can you [ask = } \\ 2 & \text { P: } & \text { [not- } \\ 3 & \text { C2: } & \text { = Helena [whether she: .hh }(0.5) \text { well = } \\ 4 & \text { P: } & \text { [not too good } \\ 5 & \text { C2: } & \text { = how she thinks Mister } \\ 6 & & \text { Baker would have responded } \\ 7 & & \text { to the offer of the } \\ 8 & & \text { operation .hhh if he was (.) had } \\ 9 & & \text { just the knowledge that we have now } \\ 10 & & \text { that we don't know whether it would } \\ 11 & & \text { (.) trigger off but it certainly was } \\ 12 & & \text { taken into consideration .hhh how } \\ 13 & & \text { would he have weighed up }(0 . \overline{8}) \text { would } \\ 14 & & \text { he have had the opera[tion. } \\ 15 & \text { P: } & \text { [.hhhh } \\ 16 & & \text { (1.0) } \\ 17 & \text { C2: } & \text { [And I want Helene to [give and then }=\end{array}$




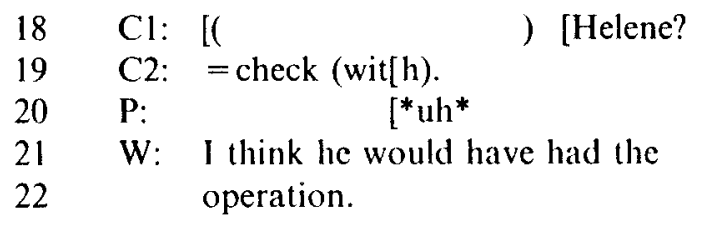

The first indication of $\mathbf{P}$ treating himself as particularly involved in the C2`s enquiry appears at line 6 , when $P$ nods slightly simultaneously with the latter part of C2's word 'responded' (nod not shown in the transcript). The core moments as regards $\overline{\mathrm{P}}$ acknowledging his ownership are, however, at lines 13-17:

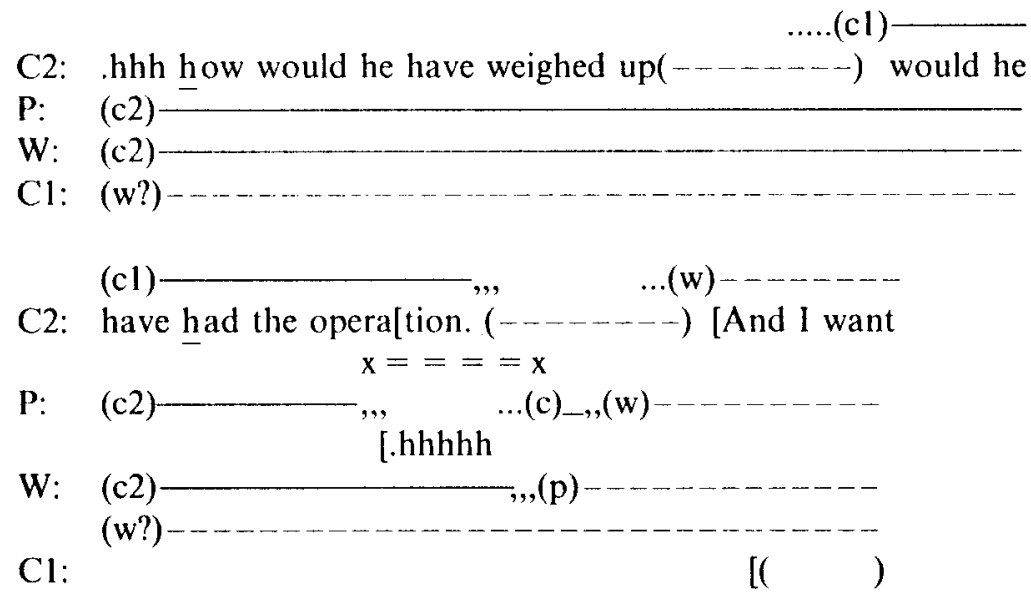

(Here, ' $\mathrm{x}=========\mathrm{x}$ ' indicates where $\mathrm{P}$ lifts up his head.) The participation structure of this excerpt is complicated indeed: $\mathrm{C} 2$ is asking $\mathrm{Cl}$ to make an enquiry to $\mathrm{W}$ about $\mathrm{P}$ 's reactions in an hypothetical situation. $\mathrm{Cl}$ is then the primary address of C2's turn; in addition to the third person form that $\mathrm{C} 2$ uses in reference to $\mathrm{P}$ and $\mathrm{W}$, this is also displayed by $\mathrm{C} 2$ when she directs her gaze towards $\mathrm{C} .1$ in the course of the turn. $\Lambda$ s the response from $\mathrm{Cl}$ is delayed resulting in a gap after $\mathrm{C} 2$ 's request. $\mathrm{C} 2$ re-orients towards $\mathrm{W}$ and produces the agenda statement (lines 17-19).

In spite of the apparent fact of not being the recipient of C2's turn, $P$ chooses to produce particular activities in the course of its production. When $\mathrm{C} 2$ is approaching the completion point of the first part of the request, $\mathbf{P}$ lifts his head up and produces a conspicuous inhalation. $\mathrm{P}$ here, just like $\mathbf{P}$ in excerpt 1 , produces his audible response just after having abandoned the gestural orientation to the speaker, and before adopting an orientation to any other participant. A few moments later, 
when $\mathrm{C} 2$ has completed the agenda statement, $\mathrm{P}$ responds again, now with a subdued *uh* (line 20). Our interpretation is here, too, that by his responses, $\mathrm{P}$ displays his involvement in the issues addressed.

As a summary of the two cases examined above, it seems that the owners can respond to the references to their experience in a particular way, which displays involvement in what is talked about, even when the owners do not hold the role of an addressee. The main work in the production of this kind of responses is of course done by the owners themselves; but their activities are supported by and concerted with those of the other participants. By displaying the owner's involvement, these collaborative activities project the possibility of the owner producing a more elaborated response later.

\section{Truncated sequences}

The owners of the experience may, however, display an orientation to their privileged right to respond to the descriptions of their experience also in a more dramatic way. This involves a departure from the questionanswer pattern usually prevailing in these counselling sessions. Instead of waiting for the counsellor to elicit their response, the owners in a number of cases volunteer it. This implies that the standard four-part sequence is truncated into a three- or two-part one.

The owners' self-initiatory activity betrays an orientation that their authoritative response to the description is due, regardless of the counsellor's questioning.

A three-part sequence appears when the owner of the experience makes a turn begimning immediately after the other patient has completed the description of the owner's experience. That is the case in (14).

(14) (E3-23: 33-)

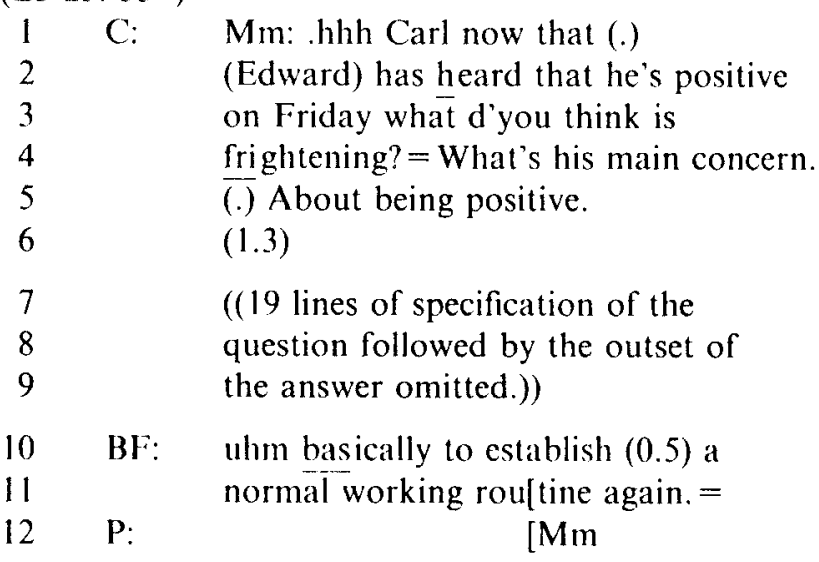




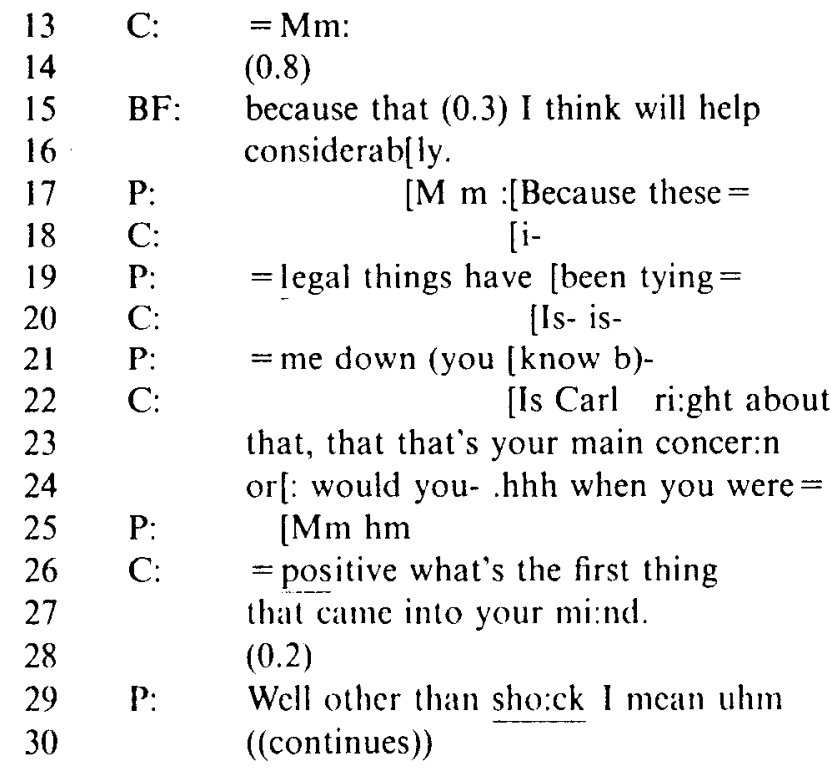

In (14), P displays his ownership of the experience under discussion in two complementary ways. First, in line 12, he produces a receipt object $\mathrm{Mm}$ while BF (his partner) is under way of producing the description of P's experience. The receipt object is produced in proximity to a possible completion point of BF's utterance, and so it works as a 'continuer' (Schegloff, 1981). By producing the continuer, in spite of not being the questioner, $\mathrm{P}$ may claim the position of a potential next speaker after $\mathrm{BF}$ (cf. Heritage and Greatbatch, 1989). In line 17, after BF has completed the description of P's experience, $\mathrm{P}$ first produces another continuer, and in the absence of further talk from BF, immediately thereafter initiates his response. P's turn is designed as a continuation of BF's version of himself, as it begins with 'Because ...'

Apparently, P's self-initiative activity here is resisted by the counsellor. After $\mathbf{P}$ has produced the continuer in line 12, the counsellor quickly produces another continuer in line 13. By doing this, she probably seeks to confirm her role as the intermediary of the interaction, and thereby, as the next speaker. (Note the same pattern above in (1), lines 11-12, where P's 'Mm:' if followed by C's 'Oka:y'.) Similarly, C resists P's uninvited turn beginning from line 17 onwards. After some overlapping talk, C manages to get the upper hand, and she then produces a question addressed to $P$ (lines 22-24 and 26-27).

The counsellor doesn't resist P's response as such: after having gained the floor, she herself ends up by eliciting a response from $P$. Instead, the 
C seems to resist the self-initiatory production of such response. In other words, in this extract the fundamental dissonance between the activities of $\mathrm{C}$ and $\mathrm{P}$ does not concern P's right to respond to a version about himself, but rather it concerns the sequential location and thematic focusing of such a response. While $P$ begins to tell his own experience immediately after his partner delivers a version of it, $C$ seeks to maintain herself as the intermediary of the interaction. As the intermediary, $\mathrm{C}$ will be able to focus the P's response to BF's initial description: she re-directs P from 'these legal things' towards 'the first thing that came into your mi:nd'.

In an extreme case, the owner of the experience may display his or her privileged right to produce a description of his/her experience by passing by the partner's version of it (initially elicited by the counsellor) altogether. That is happening in (15).

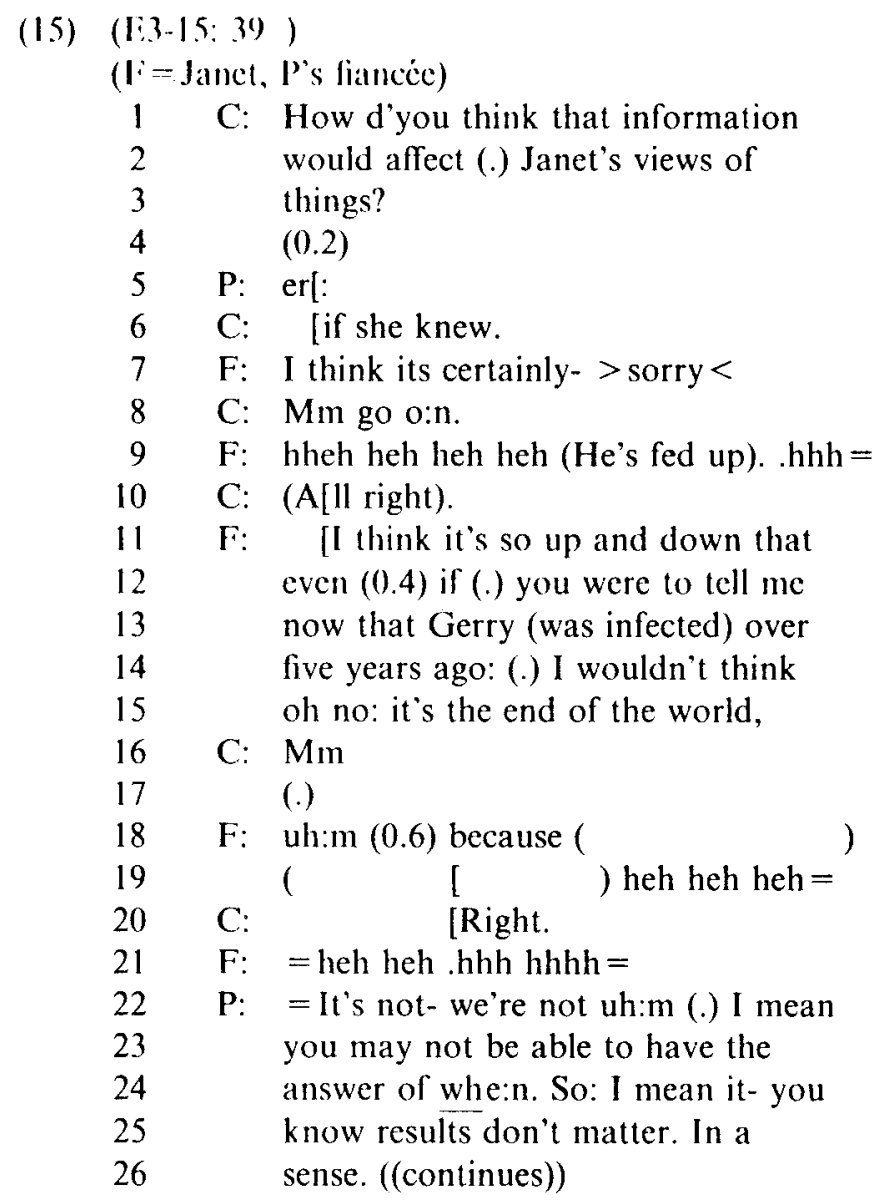


Here the $C$ initially invites $P$ to produce a version of $F$ 's inner experience, asking how it would affect his fiancee if they would have certain information (lines 1-3). The preceding talk (data not shown) makes it clear that the question is about the time of P's infection, which might have implications for his life-expectancy. $\mathrm{P}$ has raised the question by reporting that his mother would be interested to know this. So he is in process of indirectly soliciting sensitive information from the counsellors about his medical status.

After a short hesitation by the $\mathrm{P}, \mathrm{C}$ produces an extension of her question (line 6). After the expansion, $F$ makes a voluntary turn beginning, which, however, is quickly aborted and followed by an apology: 'I think its certainly- $>$ sorry $<$.

When volunteering her turn, F obviously violates the counsellor's choice of recipient of her question. This violation is recognized and repaired through the apology, and the ensuing permission given by $\mathrm{C}$ for F to go on speaking. Thereafter F produces her own account of her (future) experience. $\Lambda$ s a result of this particular trajectory, the owner's version of her mind did not only end up occupying the authoritative last position among the descriptions, but it also was so located that the production of the partner's version was suppressed.

Like all other owners of experience, $F$ in (15) oriented to her right to give the authoritative account of her experience. However, in displaying this ownership, she acted differently from the other patients: only she suppressed the production of the partner's description.

She may have good interactional reasons for doing this. Her account '(He's fed up)' probably doesn't help us very far in examining those reasons. What the account shows, is that $F$ oriented to this suppression as something accountable.

F's reasons for immediately describing her own experience, instead of waiting first for the parnter's description, may be related to the nature of the activity in which this exchange was embedded. $P$ has tried to solicit sensitive information from the counsellors. C's question 'How d'you think that information would affect (.) Janet's views of things? ((..)) If she knew', may have put $P$ in an awkward position, regarding the display of his moral self in the conversation.

In principle, an account of 'no worries' would have been coherent with his pursuit of gaining the information. But had he answered that way, he could have heard to be insensitive to his fiancée's possible suffering because of P's illness. In this sense, a 'no worries' report from P, given the activity underway, would have risked being heard as either insincere or insensitive. On the other hand, had he answered that F would be 
worried, then he could have been heard to have been pursuing something (information of the statistical life expectancy) that would cause anxiety to his partner. Also the optimism they both displayed throughout this interview would have been undermined.

In this sense, $\mathrm{P}$ is in a very difficult position in trying to construct an answer to C's question. A 'no worries' report would support his pursuit of information, but it would possibly have negative implications. On the other hand, $\mathrm{F}$ is free to report that she would not be worried. If she herself says that, the problems of insensitivity or insincerity don't appear. Consequently, F may have hurried to produce her response before $P$ produces his account at all.

Regarding the issues related to the ownership of experience, this particular case shows that the participants, in orienting to the owner's privileged right to response, can also meke use of this right, in order to manage the interational contingencies and sensitivities related to the issues addressed in the sessions.

\section{A deviant case: doubt cast on owner's description}

(16) (E3-34)

\begin{tabular}{|c|c|c|}
\hline 1 & $\mathrm{C}:$ & Okay. And could you say that Cliff has \\
\hline 2 & & lived .hh arou:nd and with Gra[ham = \\
\hline 3 & W: & $-[\mathrm{Mm}$ \\
\hline 4 & C: & $=$ for ' $x$ ' number of year:s. hh And \\
\hline 5 & & that you wouldn't allow your own son \\
\hline 6 & & [to if you weren't $($.$) convinced =$ \\
\hline 7 & W: & {$[\mathrm{Mm}$} \\
\hline 8 & $\mathrm{C}:$ & $=$ that that was (.) all right? \\
\hline 9 & W: & $\mathrm{Mm}$ \\
\hline 10 & & $(0.5)$ \\
\hline $\begin{array}{l}11 \\
12\end{array}$ & C: & $\begin{array}{l}\text { A re you convinced that that's all } \\
\text { right? }\end{array}$ \\
\hline 13 & W: & I am yeah:. \\
\hline 14 & & (.) \\
\hline 15 & C: & D'you thin[k she's convinced that = \\
\hline 16 & W: & \\
\hline 17 & $\mathrm{C}:$ & $=$ that's all right Graham. \\
\hline 18 & P: & Well I think she is now:, (.) but I \\
\hline 19 & & mean it's like (you know) yes you \\
\hline 20 & & wake up at three o'clock in the \\
\hline
\end{tabular}




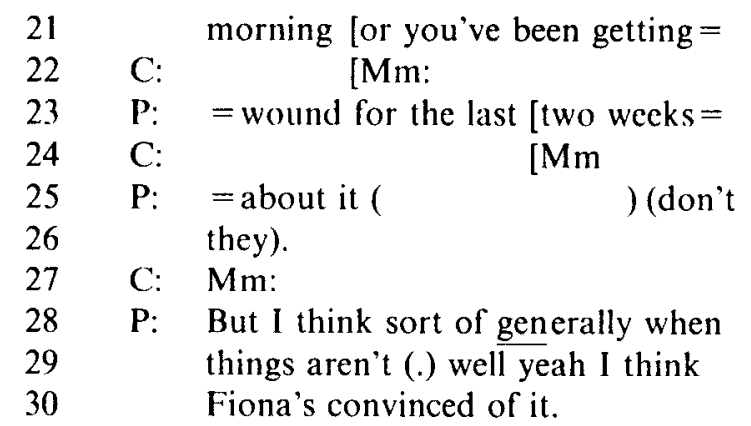

This is the deviant case referred to in the beginning of the paper. It is the only case where the owner of the experience first gives her account of her experience; and thereafter her partner produces his version of it. In other words, here the partner's experience is given the authoritative last position.

However, there are local factors that the participants are demonstrably attending to here. In the first place, the activity underway in (16) seems to be different from that in the earlier extracts. In the cases shown earlier, the participants were involved in exploring and disclosing experience, whereas here the activity is closer to what Jefferson (1985) called 'inquisition' and Silverman (1987) 'charge-rebuttal sequence', as the account of one party about her mind is treated as questionable.

The conversation in (16) is about the risk possibly attached to W's son (Cliff) when living in the same household with W's husband (Graham) who is HIV-positive. Cliff's teacher has raised the question whether it is 'safe' for the child to live in that environment. (The tape is from year 1986, when knowledge about the transmission of HIV was not very widely spread.) In lines $1-8, \mathrm{C}$ suggests an argument that $\mathrm{W}$ could use to convince people that there is no risk attached to the boy: And could you say that Cliff has lived .hh arou:nd and with Graham for ' $x$ ' number of year:s. .hh And that you wouldn't allow your own son to if you weren't (.) convinced that that was (.) all right?'

W's response to this formulation is minimal. In line 9 , she produces only an acknowledgement token $\mathrm{Mm}$, whereafter a gap of half second ensues. This vagueness and delay bears the typical characteristics of a dispreferred response (Pomerantz, 1984; Levinson, 1983): a disagreement with C's formulation is hereby conveyed.

C's next turn shows that she has recognized the possible disagreement tokens present in W's initial response. She now addresses directly the possibility of W not agreeing with C's initial formulation, by eliciting a focused description of W's state of mind: 'A re you convinced that that's 
all right.' However, now $\mathrm{W}$ reports that she is convinced about that. But even now the aflirmation in line 12 is in a minimal form, still maintaining the sense of less than full commitment by W.

It is in this local environment, characterized by ambiguity, that $\mathrm{C}$ chooses to elicit P's account of W's experience after W has herself reported it. $\mathbf{P}$ is hereby given the authorized last position in describing W's experience. P's turn between lines 18 and 30 spells out more clearly the ambiguity which was implied in W's initial response. Following the classic characteristics of delivering a dispreferred alternative (see also Sacks, 1987), P first produces a hesitation ('Well'), then the agreement token ('I think she is'), and thereafter goes on spelling out the disagreement components ('but I mean ...').

In summary, the way that $\mathrm{W}$ initially responded to C's formulation cast doubt on the sincerity of her assertion. Given this doubt - which was intersubjectively oriented to by the patticipants the position of being able to give the last account of W's experience was re-allocated by C to P. If the owner conceals something, she doesn't use her right to give an authoritative account of her experience - and in that kind of local circumstances, the partner here is given the last word.

\section{Counselling and family as parallel contexts}

Thus far we have been examining the turn-by-turn dynamics involved in the sequences where one of the clients is asked to describe the experience of another. The findings thus far can be summarized as follows: The owner of the experience is regularly given the last, authoritative position in the sequence of descriptions. All the participants (the counsellor eliciting the description, the patient giving the description, and the patient about whom the description is) collaboratively display that the first description is tentative and waiting for confirmation by the owner.

Now it is time to broaden the scope of the argument in order to examine the conditions and consequences of these displays. References to two related conversation analytical studies are due here.

Following the line of reasoning initiated by Sacks in his lectures, Anita Pomerantz (1980) was among the first to give systematic consideration to phenomena like those examined here. Pomerantz argues that descriptions of events displaying their producer's 'limited access' to the relevant facts may work as a device for inviting the other party to disclose his/ her authorized version of the same issues (assuming, of course, that the other party is in a position of having such privileged access to the relevant facts). Such dynamics are at work in cases like the following. 
(17) (Pomerantz, 1980)

I B: Hello:..

2 A: $\quad$ HI::.

3 B: $\quad$ Oh:hi:: 'ow are you Agne::s,

4 A: $\rightarrow$ Fine. Yer line's been busy.

5 B: $\quad$ Yeuh my fu (hh) - hh my father's wife

6 called me hh So when she calls me::

7 .hh I can always talk fer a long

8 time. Cuz she c'n afford it'n I

9 can't. hhh heh .ehhhhhh

In (17), the description based on a limited access to relevant facts given by $\mathrm{A}$ (marked with an arrow) works as what Pomerantz called 'a fishing device', successfully eliciting B's insider's report in the next turn.

Recently, Bergminn (1989) has applied a similar perspective to an analysis of psychiatric intake interviews in German hospitals. He shows how the psychiatrists tell their patients something about their view of the patient's situation (the psychiatrist's view being based on direct observation, referring doctor's notes, or the like). They mark their views as uncertain. The patients respond to these tellings by disclosing their own interpretation of their situation. Bergman concludes that presenting his knowledge as fragmentary and uncertain, the psychiatrist invites or encourages the recipient to deliver an 'authentic' version. Doing this, in turn, is something that the psychiatrists are expected to accomplish as a part of their professional conduct.

The AIDS counsellors, just like Bergman's psychiatrists, are practitioners whose professional task is to elicit patients' talk. Most of the time in AIDS counselling sessions are spent talking about sex, illness or dying - all topics that are difficult to address in ordinary conversation. In the clinic from which these materials are collected, the counsellors' theories related to their work emphasize the importance of eliciting clients' own fears related to their future (Bor and Miller, 1988). Much of the professional competence of a counsellor is related to an ability to break through the boundaries of not speaking (cf. Nelson-Jones, 1988). ${ }^{8}$

Now the simplest vehicle for eliciting someone's description of his/her fears or other inner feelings is naturally a question. Questions are, indeed, extensively used in the counselling sessions applying the family systems approach. And in most cases, the questions are successful: patients answer them, and by answering questions on 'difficult' topics, they produce talk on such topics.

Even though a counsellor's question creates a strong sequential implication for the patient to produce an answer, it still can be circumvented so 
that extended talk on the topic proposed by it will not (immediately) be achieved. In (18), W is strongly resistant to talking further about the concerns she has just disclosed about her husband developing AIDS.

(18) (E4.016)

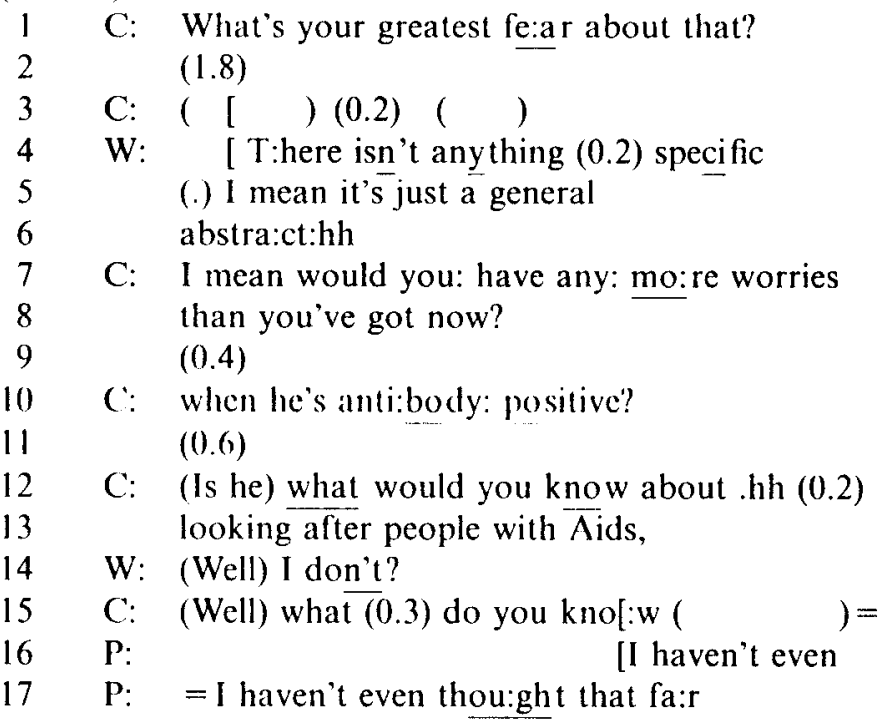

Here $W$ displays a reluctance to detail her fears about taking care of her husband as a potential AIDS patient. In many cases like this, instead of answering the C's questions, the clients produce an account for not answering, thus trying to avoid disclosing their experience or details of it.

Our suggestion is that asking a client to produce a version about a coclient's experience can serve as an applicable means of avoiding troubles like this.

There seem to be two alternative formulas in achieving a patient's account of his/her experience. The apparently simpler formula is based on question and answer:

(1) C: Asks a question

(2) P: Produces an answer

The apparently more complicated formula is based on the sequence we have been analyzing here:

(1) C: Invites P1 to produce a description of something related to P2's expererience

(2) P1: Produces the requested description

(3) C: Invites P2 to respond to the description given by $\mathrm{P} 1$

(4) P2: Produces the response 
Both formulas can be used when inviting the patient to talk about his or her delicate concerns. Our hypothesis is that the complicated formula can be more powerful in reaching this aim.

As we saw above, a question can be turned down by producing an account for not answering. Now of course the moves suggested by the counsellor in the more complicated formula can equally be turned down - but there are reasons for thinking that this will only happen at considerable moral and interactional costs.

Let us begin from the end of the more complicated formula. This far we have not found any cases where a patient has not responded after a version of his or her mind has been given by a co-client. The only variation is that while in the majority of cases the response emerges only after the invitation has been made by the counsellor, in a minority of them the 'owner' responds voluntarily.

Why is there such a strong sequential implication between the description of another client's experience and the owner's response? Our suggestion is that in these cases, the patient is exposed to a double expectation to produce talk. Not only is the counsellor inviting him or her to respond (stage 3), but equally his or her co-client is doing this. The version of the patient's experience (stage 2) produced by the co-client works as a 'fishing device'.

As we have seen in the previous sections, all participants have collaboratively recognized the owner's special status as regards the description given by another person about the owner's experience. This recognition works now as the publicly displayed basis of an expectation for the owner to produce the authorized description of the experience in question. In other words, by having encouraged a client to give a version of another's experience, the counsellor has managed to integrate one client into the work of inviting the other to speak. The expectation to speak is then not only coming from the professional 'doing counselling', but also from the client's own partner; and this expectation has been confirmed by all participants in the verbal and nonverbal ways they used to recognize the ownership of the experience.

But there remains another question. If the occurrence of P2's talk on potentially delicate topics is more likely to appear after $\mathrm{P} 1$ has given his or her version of P2's experience, it may be that the focus of the difficulties in inviting patients' talk is only moved into another direction. Perhaps the counsellor already faces troubles when inviting $\mathrm{Pl}$ to give a version of $\mathrm{P} 2$ ?

The only empirical evidence we have here is that the patients regularly do give their versions of their relations when asked. Apart from adolescent patients, no 'resistance' is usually found here. ${ }^{9}$ Our hypothesis is that the 
counsellor inviting a patient to produce a version of another patient trades off a strong moral expectation related to what 'proper' partners should be like.

The clients participating in each session are either members of the same family, or otherwise close partners. They come to the counselling sessions in order to find help and to support each other in their predicament. In these circumstances, being able to produce a version of another person's experience can be counted as an indication of a close and intimate relation between the producer of the version to the one whom it is about. To put it into the terminology of Harvey Sacks (1972), describing the experience of your partner appears, then, as a category hound activity based on 'standard relational pairs' like husband :: wife, or boyfriend :: boyfriend.

It may be an indication of a good partnership if you have a capacity to produce an account of the inner experience of your relation (and if you indeed use this capacily). And even more: it may be an indication of a particularly close and caring partnership if you produce an account in which her or his intimate thoughts and feelings are included in a sensitive way. Actually the fact that persuasion as in (18) is not needed when the 'owner' is present may be additional evidence for this: when the owners are present, the expectation to display good partnership is of course more immediate and strong.

In these sequences, the clients giving descriptions of others' experience are engaged in an activity that resembles closely what Pomerantz (1980) called 'fishing'. The crucial difference, however, is that while persons doing 'fishing' pursue their own local interactional goals, the clients describing others' experience rather end up being part of a strategy set up by somebody else, namely the counsellor. Given the 'standard relational pairs' that clients attend to, the one invited to describe other's experience may find it very difficult not to be part of that strategy.

As a summary, then, in the sequences examined in this paper, there are two types of extra constraints placed upon the patients to produce talk. First, there are the constraints placed upon the producer of the description of other's experience. Not producing the elicited description would be negative evidence about the relationship between the producer and the owner. Second, there are the constraints upon the owner to respond. It is hard for the owner to say that he cannot answer, because the other party with the limited access to the relevant facts has already been able to talk. It is equally hard for him to resist the topics introduced in the counsellor's question and the other party's description, because now the topic already is there. Failing to respond would then be an even more accountable matter than failing to answer to straightforward questions. 
The success of $\mathrm{C}$ in ( 1 ) in eliciting P's fears may be gained through the exploitation of this kind of constraints. P's revelation of his 'greatest fear' is preceded by the elicitation and production of P's boyfriend's version of P's worries. Given this background, C, when finally eliciting P's response, does not need to ask sensitive questions which might possibly carry a sense of intrusiveness. C doesn't even focus on P's inner experience in her question; she simply enquires about P's knowledge of the future possibilities. This question triggers off the extended account by $\mathrm{P}$ about his fears.

Asking patients to describe the experience of their relations can be a powerful way of inviting patient's talk on sensitive matters. In the ordinary question-answer sequence, responding to an invitation to talk is a moral matter ${ }^{10}$ within the framework of a conversation in general, and probably a client-professional relation in particular. In the sequences analyzed here, it is a moral matter also within the framework of relations between lovers, family-members, or the like. Exploiting this moral sphere within the counselling sessions seems to be very effective, and perhaps a characteristic feature of the Family-Systems Theory approach.

According to Schegloff (1987), the context of interaction should be treated as something locally achieved rather than externally imposed. Social analysts should try to find out how the participants of an interaction 'display in their conduct which of the indefinitely many aspects of context they are making relevant'.

In the sequences analyzed here, the participants skilfully interlock invocations of two different contexts and related identities: a professional-client encounter and family/partner interaction. By asking questions, the counsellor displays professionality and invites others to constitute themselves as 'clients'. The patients collaborate by providing opportunities for the counsellor to ask questions and by answering them (for details, see Peräkylä and Silverman, in press). Simultaneously, the counsellor treats the coparticipants as 'family' or 'partners' by asking one to tell the experience of the other. In a similar fashion, the patients treat themselves as 'family' or 'partners' by telling the other's experience or allowing it to be told.

Managing and making use of the simultaneous invocation of these two contexts is one of the admirable aspects of the professional activity of counselling.

\section{Conclusion}

A rule stands there like a sign-post. - Does the sign-post leave no doubt open about the way I have to go? Does it shew which direction I am to take when I have passed it; whether along the road or the footpath or cross-country? But 
where is it said which way I am to follow it; whether in the direction of its finger or (c.g.) in the opposite one? - And if there were, not a single sign-post, but a chain of adjacent ones or of chalk marks on the ground - is there only one way of interpreting them?

Wittgenstein (1968, para. 85)

Our analysis of these transcripts has not led to the conclusion that the talk of counsellors and clients is governed by any set of rules. Instead, we have seen all parties skilfully using rules rather like Wittgenstein's sign-posts. People do defer to their partners' special right to their ownership of their own experiences; but they do so through a variety of ways. Professionals do recognize the embeddedness of their clients in family identities but they do so through means which serve to achieve counselling goals.

Since at all times the sense of what the parties are saying is sequentially localed, the speaker's words also are treated as a form of sign-post which points in the direction of certain possibilities and away from others. So we are not dealing here with a communion of minds. As Wittgenstein elsewhere tells us 'understanding is not a mental process' (1968, para. 154). We should not, therefore, accept a model of human communication as a mutual transference of thoughts or sentiments. The example of human-computer interaction powerfully underlines how communication can proceed via the uptake of signals or cues whose meaning is contextually determined. This, of course, does not deny that members interpret speech as the product of another's consciousness. Indeed, it is difficult to picture a situation where this is not the case. However, it does suggest that analytically we do better to understand the complex interpretive work involved in sequencing talk without access to the mental states of another. The participants reach mutual understanding and a shared intersubjective world, to a degree that is good for 'all practical purposes', through the interplay of their public actions (cf. Heritage, 1984: 54-61).

Elsewhere, Wittgenstein discusses the case of a man called $B$ who suddenly says. 'Now I know how to go on.' We can make sense of this utterance by treating it as a 'signal'. So it does not describe B's mental state. Instead, its meaning is local and sequential:

This is how these words are used. It would be quite misleading in this last case, for instance, to call the words a 'description of a mental state'. - One might rather call them a 'signal'; and we judge whether it was rightly employed by what he goes on to do.

Wittgenstein (1988, para. 180)

In collaboratively projecting a patient's account of his experiences, counsellors and clients co-produce signals which invite (and usually obtain) 
the desired patient's response. In doing so, they also reproduce versions of themselves (as counsellors, patients and partners) and of a world in which parties have a special access to their own experiences. Ironically, then, the very building block of romantic sociologies - the uniqueness of personal experience - turns out to be a managed social accomplishment.

That accomplishment is always located in specific practices and contexts. In this paper, we have merely implied how the description of other persons' experience can be embedded in a number of contexts the re-enactment of professional-client encounters which seek to manage AIDS-related behaviour in the context of the theory and practice of 'family therapy'. Change one of those contexts and who speaks what about experience will vary. Heath (1989) has shown how the expression of pain in medical consultation is embedded in the turn-taking structure and participation framework of the consultation: the production and reception of 'pain cries' is synchronized with the progression of the diagnostic activity. Indeed, in certain contexts, caregivers can speak unproblematically for another's mind:

Hidden as it is, mind must be spoken for. As the Alzheimer's disease experience plainly shows, persons may not be able to speak their own minds ... In the Alzheimer's disease experience, of course, the caregiver is a key spokesman, his/her assertions warranted by intimate daily contact. At times, the patient may also serve as agent for his own mind; at other times, his/her very vocal, insistent, or seemingly intelligible testimony on his/her own behalf may be discounted because of his/her disease. There is no guarantee, in practice, who will serve or be accepted as mental agent, only that mind emerges by way of agency.

Gubrium (1986: 43)

As Gubrium shows, in Alzheimer's Disease and, more broadly, in what he calls 'the professionalization of mental concern' (1986), the production and circulation of 'experience' is institutionally embedded. We can see the force of this embeddedness simply by comparing how 'experience' is talked about between mental health professionals and their clients and between news-interviewers and their 'clients'. In these cases, not only do speakers face different audiences or populations but they use different technologies. The Foucauldian implications are clear but, unfortunately, beyond the scope of this paper. ${ }^{11}$

Critics may feel that, in this new turn, we have contradicted Wittgenstein's assertions about the primary status attached to persons' own versions of their 'experience'. Perhaps the varying institutional contexts of talk render defeasible any general account of the language-game of 'experience'. 
However, in recognizing this, we still must acknowledge Wittgenstein who, time after time, directs our attention to the varieties of uses associated with any term. Consider his reported remarks, when asked about his views on Hegel:

No, I don't think I would get on with Hegel. Hegel seems to me to be always wanting to say that things which look different are really the same. Whereas my interest is in showing that things which look the same are really different. I was thinking of using as a motto for my book a quotation from King Lear: 'I'll teach you differences'.

Drury (1984: 157)

Inspired by Wittgenstein, the study of the multiple ways in which experience is assembled points to a reassessment of the tasks of the cultural sciences. In a post-modern world, our gaze shifts away from laws which establish similarities towards a play of endless differences.

\section{Appendix: The transcription symbols}

C2: quite a [while
Mo: $\quad$ [yea
$=\quad \begin{aligned} & \text { W: that I'm aware of }= \\ & \mathrm{C}:=\text { Yes. Would you } \\ & \text { confirm that? }\end{aligned}$

Left brackets indicate the point at which a current speaker's talk is overlapped by another's talk.

Equal signs, one at the end of a line and one at the beginning, indicate no gap between the two lines.

Yes $(0.2)$ yeah

Numbers in parentheses indicate elapsed time in silence in tenths of a second. cates a tiny gap, probably no more than one-tenth of a second.

What's up?

Underscoring indicates some form of stress, via pitch and/or amplitude. 


$\begin{array}{ll}:: & \text { O:kay? } \\ \text { WORD } & \text { l've got ENOUGH TO } \\ & \text { WORRY ABPOUT }\end{array}$

hhhh

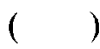

(word)

$((\quad))$

?

uhu? and life ( ) anything positive tinues))

Colons indicate prolongation of the immediately prior sound. The length of the row of colons indicates the length of the prolongation.

Capitals, except at the beginnings of lines, indicate especially loud sounds relative to the surrounding talk.

I feel that (0.2) hhh A row of h's prefixed by a dot indicates an inbreath; without a dot, an outbreath. The length of the row of h's indicates the length of the in- or outbreath.

future risks and ( ) Empty parentheses indicate the transcriber's inability to hear what was said.

Would you see (there) Parenthesized words are possible hearings.

confirm that ((con- Double parentheses con-

tain author's descriptions rather than transcriptions.

Asterisk in both sides of a word indicate that it is uttered at a low volume in contrast to the surrounding talk.

Punctuation marks are used to indicate intonations, not as grammatical symbols. For example, a question may not necessarily have a rising intonation and would not receive a question mark. 


\section{Anssi Peräkylä and David Silverman}

\section{Notes}

* We wish to acknowledge the financial support of Glaxo Holdings plc, the English Health Education Authority and the Academy of Finland for the research upon which this paper is based. We are most grateful for the helpful comments of Paul Drew, David Greatbatch, Jaber Gubrium, Cristian Heath, John Heritage, Anita Pomerantz and Gary Wickham. Regarding the future academic use of this material, we would like to acknowledge that Silverman is mainly responsible for the Introduction and Conchusion, and Periakylia for the rest of the paper.

1. Wittgenstein's playful observation suggests the logical possibility of a sociology of leaves - admittedly, probably less interesting than a sociology of machines but an example which reveals our muddy thinking about undes standing others.

2. As Paul Drew has pointed out to us, these preparations would be interesting in their own right. The statement component inserted between the two formulations of the question may work to elicit a special kind of 'troubles-related' answer.

3. As Paul Drew has pointed out to us, this particular link between the organization of knowledge and secquential pattern of eonversation may apply only to the description of inner states of mind. The organization of knowledge concerning ofher types of objects -. c.g. shared life events that both clients as spouses or partners may have their own perspectives on -- is likely to be reflected in different kinds of sequential patterns. A classic example is provided by Sacks (1971) analysis of spouses teiling stories, to a third party, about events they both were party to: here we find e.g. onc spouse correcting the utterances of another. In our data, a patient's descriptions of nonmental matters related to him/herself is sometimes followed by a description by the partner about the same issues. This is the case in the following.

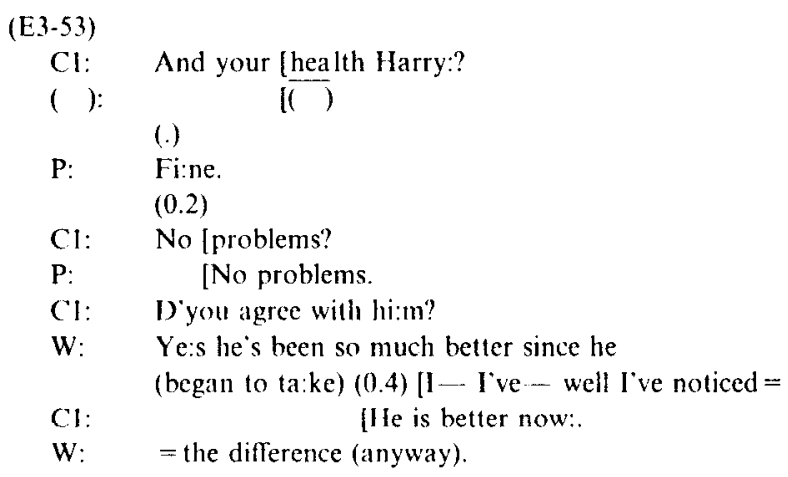

In the extract above, the counsellor invites the patient's wife to respond to the patient's initial description of his health. The patient's health is thereby treated as a public phenomenon, on which his wife may have a valid and perhaps different perspective.

4. The semantic focus of the question can be heard in two ways. It may be related to P's inner experience at work: but it also may be related to things happening at P's work. This is not important regarding the argument here

5. This is not to say that all questions or descriptions related to the person himself would be produced in a direct way, without such embedding. Descriptions of one's own mental states are like that, but e.g. descriptions of one's own future health may very well be embedded. An example is provided by the counsellor's question in (1), line 
26-28: her enquiry is about something that the $P$ is not expected to have first hand knowledge, and accordingly, the question employs an embedded structure.

6. We have decided to use our own variation of the conventional notation in transcribing body movement. We have used the symbols '_____. ' and '____ interchangeably for describing a person's orientation towards another person. By using two different symbols for orientation to persons, we can indicate easily the shift of orientation from one person to another, which is crucial for our analysis here. At the beginning of each line, the person whom the subject orients to is indicated by letters in brackets. Thus ' $(w) \ldots \ldots$ ' and ' $(w) \ldots$ indicate equally that the subject is garing at $W$ (wife). The notation ' $m d$ ' indicates Middle Distance Position, where the subject is posturally oriented to nobody.

7. The relatively bad quality of the visual side of this recording prevents us from transcribing the postural orientation of $\mathrm{C}$, who sits with her back towards the camera

8. Note, however, that in the theory and practice of family systems theory, achieving clients talk is not an explicit aim. The therapists invite talk through circular questioning and other methods, in order to illuminate and set into motion the family's patterns of relations. coalitions and atlipmments. This is obviously the uthimate goal also for the AII SS counsellors applying the family-systems approach. In this paper, however, we have to confine ourselves to examining the narrower goal, encouraging patients talk; which indeed is a pre-requisite for achieving the more elaborated family-therapcutic goals.

9. Not even (15) constitutes an exception. P there doesn't display much reluctance to produce a version of F's experience. Perhaps F's intervention took place because the constraints for $P$ to produce a version of $F$ 's experience were so strong. that he would otherwise have been compelled to produce such a version, with the negative moral implications cxamined above.

10. We follow here the ethnomethodological usage of the term 'moral', emphasizing that the participants orient to patterns of interaction, such as the adjacency of a question and an answer, as normative matters (Drew, 1990).

11. For instance, we might study how certain legal arrangements provide for the possibility of owning 'experience'. Gary Wickham has pointed out to us, for instance, that there is evidence that, in antiquity, slaves could only own 'experience' in utterances produced under torture.

\section{References}

Abrams. P. (1984). Evaluating soft findings: Some problems of measuring informal care Research, Policy and Plaming. 2(2): 1.8.

Ball. S.J. (1984). Beachside reconsidered: Reflections on a methodological apprenticeship. In The research process in Educational Settings: Ten Case Studies, R.G. Burgess (ed.), London: Falmer.

Bergman. J.R. (1989). Veiled morality: notes on discretion in psychiatry. In Discourse in Professional and Everyday (utture, P-A. Forstorp (ed.), 23-46. University of Linkoping, Studies in Communication, SIC 28.

Bloor, M. (1983). Notes on member validation. In Contemporary Field Research: A Collection of Readings, R.M. Emerson (ed.), 156-172. Boston: Little Brown.

Bor, R. and Miller, R. (1988). Addressing 'dreaded issues': A description of a unique 
counselling intervention with patients with AIDS/HIV. Counselling Psychology Quarterly 1: 397-405.

Coulter, J. (1979). The Social Construction of Mind. Studies in Ethnomethodology and Linguistic Philosophy. London: Macmillan.

Drew, P. (1990). Conversation analysis -... Who needs it. Text 10 (1/2): 27-35.

Drury, M. O'C. (1984). Conversations with Wittgenstein. In Recollections of Wittgenstein, R. Rhees (ed.), Oxford: Oxford University Press.

Finch, J. (1984). It's great to have someone to talk 10: The ethics and politics of interviewing women. In Social Rescarching, C. Belf and H. Roberts (eds.). London: Routledge.

lrake, C. (1972). How to atsk for a drink in Subanun. In Language and Social Comber, P.P. Giglioli (ed.). Harmondsworth: Penguin.

Garfinkel, H. (1967). Studies in Ethmomethodology. Englewond Cliffs. NJ: Prentice Hall

Goffman, E. (1981). Forms of talk. Oxford: Basil Blackwell.

Goodwin, C. (1979). The interactional construction of a sentence in natural conversation. In Everyday Language: Studies in Ethmomethodolog., G. Psathas (ed.), 97-21. New York: Erlbaum.

Goodwin, C. (1981). Conversational Organization: Interaction Between Speakers and Hear(rs. New York: Academic l'ress.

-. (1984). Notes on story structure and the organization of participation. In Structures of Social Action: Sumties in Comersation Amalysis, J.M. Alkimson and J.C. Heritage (eds.), 225 246. Cambridge: Cambridge University Press.

Gubrium, J. (1986). The social preservation of mind: The Alzheimer's disease experience. Simbolic Interaction 9(1): 37-51.

Heath, C. (1986). Bedl. Morement and Speech in Medical Interaction. Cambridge: Cambridge University Press.

- (1989). Pain talk: The expression of suffering in the medical consultation. Social Psychology Quarterly 52 (2): 113-125.

Heritage, J. (1984). Garfinkel and Ethmomethodology: London: Polity Press.

- and Greatbatch, D. (1989). On the institutional character of institutional talk: The casc of news interviews. In Discourse in Professional and Everiday Culture, P-A. Forstorp (ed.), 47-98. University of Linkoping. Studies in Communication, SIC 28.

Hymes. D. (1964). Toward Ethnographies of Communication. American Anthropologist $66(6): 12-25$.

Jefferson, $G$. (1985). On the interactional unpacking of a gloss. Language in Sociely 14: 435. 466 .

Levinson, S.C. (1983). Pragmatics. Cambridge: Cambridge Iniversity Prfess.

- (1988). Putting linguistics on a proper footing: Explorations in Goffman's concepts of participation. In Erring Goffman: Exploring the Interaction Order. P. Drew and A. Wootton (eds.), 161-227. Cambridge: Polity Press.

Mauksch, L. B. and Roesler, T. (1990). Expanding the context of the patient's explanatory model using circular questioning. Family. Systems Medicine $8(1): 3-13$

Mills, C.W. (1940). Situated actions and vocabularies of motive. American Sociological Revien 5: 904-913.

Nelson-Jones, R. (1988). Practical Counselling and Helping Skills. Second Edition. London: Cassel.

Oakley, A. (1981). Interviewing women: A contradiction in terms. In Doing Fominist Research, H. Roberts (ed.). London: Routledge.

Penn, P. (1982). Circular questioning. Family Process 21(3): 267-280.

Peräkylä. A. and Silverman, D. (in press). Reinterpreting speech exchange systems: Communication formats in AISS counselling. Sociology. 
Pomerantz, A. (1980). Telling my side: 'Limited access' as a 'fishing device'. Sociological Inquiry 50: $186-198$.

- (1984). Agreeing and disagreeing with assessments: Some features of preferred dispreferred turn shapes. In Structures of Social Action: Suldies in Conversation Analysis, J.M. Atkinson and J.C. Heritage (eds.), 57-101. Cambridge: Cambridge University Press.

Sacks, H. (1971). The Interaction of Couples in The Telling of Stories. Lecture 4, October 19th, University of California. Irvine (mimeo).

- (1972). An initial investigation of the usability of conversational data for doing sociology. In Studies in Social Interaction, D. Sudnow (ed.), 31-74. New York: Free Press.

- (1974). On the analyzability of stories of children. In Ethnomethodology: Selected Readings. R. Turner (ed.), 216-232. Harmondsworth: Penguin.

..- (1987). On the preference for agreement and contiguity in sequences in conversation. In Talk and Social Orgamization, G. Button and J.R.E. Lee (cds.), 54 69. Clevedon: Multilingual Matters.

--, Schegloff. E.A. and Jefferson, G. (1974). A simplest systematics of turn-taking for conversation. Lamgutuge 50: 696-735.

Schegloff, E.A. (1981). Discourse as an interactional achicvement: Some uses of "uh huh" and other things that come between sentences. In Georgetown University Round Tahle on Languages and Linguistics, Deborah Tannen (ed.), 71-93. Washington, D.C.: Georgetown University Press.

- (1987). Between macro and micro: Contexts and other connections. In The Micro-Macro Link, J. Alexander, B. Giesen, R. Munch, and N. Smelser (eds.), 207-234. Berkeley and Los Angeles: University of California Press.

Selvini, M.P., Boscolo, L., Cechin, G., and Prata, G. (1980). Hypolhesizing --- circularity --neutrality: Three guidelines for the conductor of the session. Family process 19 (1): $3-12$.

Sharrock, W. (1974). On owning knowledge. In Ethomethodology, R. Turner (ed.), 45-53. Harmondsworth: Penguin.

Shibles, W. (1969). Wittgenstein Language and Philosophy, Dubuque, Iowa: Kendall/1 iunt.

Silverman. D. (1987). Communication and Medical Practice: Social Relations in the clinic. London: Sage.

- $(1989 \mathrm{a})$. The impossible dreams of reformism and romanticism. In The Politics of Field Research, J. Gubrium and D. Silverman (eds.), 30--48. London: Sage.

- (1989b). Six rules of qualitative research: A post-romantic argument. S!mbolic Imteraction, 12(2): 25-40.

Wittgenstein, L. (1968). Philosophical Investigation.s. Translated by G.E.M. Anscombe. Oxford: Basil Blackwell.

.... (1969). On Certaint!', G.E.M. Anscombe and G.H. von Wright (eds.). New York: Harper and Row.

Woolgar, S. (1985). Why not a sociology of machines: The case of sociology and artificial intelligence. Sociology 19: 557 572.

Anssi Peräkylä is Glaxo Rescarch Fellow at Goldsmiths' College. University of London. From 1986- 1988 he was involved in a research project on the care of the dying patients at University of Tampere, Finland. This project led to papers published in Sociology of Health and Illness and Qualitative Health Research, and a book recently published in Finnish. The results of his current work on AIDS counselling have been published in papers in Sociology of Healh and Illness, AIDS-Care, and Sociology. 


\section{Anssi Peräkylä and David Silverman}

David Silverman is Professor of Sociology, Goldsmiths' College, University of London. His interests range from methodology and discourse analysis to medical sociology. His most recent books are Qualitative Methodology and Sociology (Gower, 1985), Communication and Medical Practice: Social Relations in the Clinic (Sage, 1987), and The Politics of Field Rescarch: Sociology Beyond Englightenment (Sage, 1989, edited together with Jaber Gubrium). 